\title{
Stem cell therapies in multiple sclerosis - united we stand, divided we fail
}

\author{
Jagannadha R Avasarala* \\ Department of Medicine, Division of Neurology, Greenville Health System, University of South Carolina, USA
}

This brief analysis will focus on multiple sclerosis (MS), a chronic disease of the central nervous system (CNS), for purposes of discussion. Typically, MS begins as a relapsing-remitting disease (RRMS), in the majority of cases [1]. The natural progression of the disease is transition into a secondary progressive multiple sclerosis (SPMS) stage despite the use of FDA-approved medications with 'proven' effect on disability; unfortunately, none of them have any tangible or demonstrable effect on a singularly distressing symptom - irreversible disability. No matter what therapies are used, the relentless march of MS disability is almost inevitable. It is against this backdrop that stem cell research in the treatment of MS has garnered attention, and this review provides a bird's eye view of the promise and the limitations of stem cell therapies.

The pathological substrates for disability in MS are, predominantly, axonal degeneration [2] gray matter lesions/atrophy [3] as well as spinal cord gray matter lesion burden [4]. Of these, traditionally, axonal loss or degeneration has been identified as the major determinant of irreversible neurological disability. Axonal injury begins early and correlates with the degree of inflammation within lesions, indicating that inflammatory demyelination influences axon pathology during RRMS. Axonal loss can and tends to remain clinically silent for many years, and irreversible neurological disability develops when a threshold of axonal loss is reached/or compensatory CNS resources become exhausted. Most of our knowledge and current theories about axonal hypothesis come from data in animal models with primary myelin or axonal pathology, and from pathological or magnetic resonance studies on MS patients. In mice, for example, the prototypical experimental allergic encephalomyelitis (EAE) model shows that $15-30 \%$ of spinal cord axons are lost before permanent ambulatory impairment occurs. In the SPMS stage of the disease, chronically demyelinated axons degenerate due to lack of myelin-derived trophic support.

Recently, in the U.S., the Food and Drug Administration (FDA) approved of autologous, mesenchymal stem cell-derived neural progenitor cells (MSC-NPs) as an Investigational New Drug (IND) for an open label, phase I clinical trial in the treatment of MS [5]. The hypothesis and expectation of MSC-NPs is that these cells display greater potential for differentiation of mature neural tissue, act as the primary therapeutic agent, display potential for recruitment of existing stem cells in the brain and spinal cord via trophic growth factors and can be introduced into the CNS through the intrathecal route, as demonstrated in the EAE animal model of MS [6]. This study provided compelling evidence of the therapeutic potential of intrathecal MSC-NPs in mice with EAE, a corollary to progressive MS. Findings from this study showed that injected MSC-NPs migrated to areas of demyelination where they seemed to influence the rate of repair through effects on endogenous progenitors in the spinal cord. Furthermore, this study paved the way for the clinical trial design for dosing/dosing frequency. The clinical translation of this stem cell research was further advanced in a publication examining the characteristics of human autologous MSC-NPs from patients with MS [5]. This study showed that bone marrow derived MSC-NPs from MS patients are a feasible source of stem cells for clinical application and that the in vitro immunoregulatory and trophic properties of these cells may have therapeutic value in the treatment of MS.

Other approaches include the use of autologous hematopoietic stem cell transplantation (HSCT), a form of immune suppression but unlike standard drugs, is designed to reset rather than suppress the immune system $[7,8]$. One other possible avenue is human pluripotent stem cell (hPSC)-derived neural progenitor cells (NPCs), a cell population that is capable of almost limitless expansion with subsequent differentiation into the various cell types that comprise the CNS. This could provide an unlimited source of cells for cellbased therapies and disease modeling. However, the use of any type of stem cells for treatment of chronic neurological diseases requires the development of scalable and reproducible protocols for their generation, expansion, characterization, and neuronal differentiation and unless these types of methodologies are perfected, cells that could form the basis of therapeutic measures may be hard to come by. Another option is embryonic stem (ES) cells which are pluripotent, and can form all three primary germ layers (ectoderm, endoderm and mesoderm). The disadvantages of using ES cells is the potential for allogenic immunogenicity, need for specific culture conditions to maintain ES cell lines, and frequent monitoring to assure phenotypic stability [9].

However, cells possessing characteristics that could be useful as a source of stem cells is a far cry from using them to 'reconstruct' or 'rewire' a brain that has been ravaged by disease for years, if not decades. That is the challenge that stem cell therapy design has to overcome. Even if the cells do work, how do they progress from point A to point $B$ in a 3D geometric brain without scaffolding and new vascular tissue to support the framework? Proper fiber outgrowth from cells implanted into host tissue and integration into host neuronal networks is critical for functionality to be restored.

By way of comparison of how stem cells might be put to use in

Correspondence to: Jagannadha $\mathrm{R}$ Avasarala, $\mathrm{MD}, \mathrm{PhD}$, Department of Medicine, Division of Neurology, Greenville Health System, University of South Carolina, 200 B PatewoodDr, Greenville, SC 29615, Tel: 864-454-4500, E-mail: javasarala@ghs.org

Received: August 05, 2015; Accepted: September 14, 2015; Published: September 17, 2015 
an acute setting, one needs to consider acute spinal cord injury (SCI) which often causes permanent loss of function below the site of the injury. According to the National Spinal Cord Injury Statistical Center (NSCISC), automobile crashes are the leading cause of injury with the most frequent cause of neurologic injury category being incomplete tetraplegia, followed by incomplete paraplegia, complete paraplegia and complete tetraplegia. Less than $1 \%$ experience complete neurologic recovery by the time they are discharged from the hospital and a staggering 12,500 new cases occur every year. Clearly, these numbers tell us that remedial approaches would be welcome transplantation of stem cells is a promising approach in acute SCI since it may support spinal cord repair. However, in chronic SCI, since greater amounts of nervous tissue are lost, scaffold transplantation is the only option for cellular engraftment and bridging. The aim of regenerative medicine, specifically tissue engineering, is to create a microenvironment that mimics native extracellular matrix (ECM), capable of promoting specific cell-matrix interactions, coaxing cell behavior and fostering host tissue regeneration. To this end, nanostructured scaffolds are currently the most promising advanced substrates capable of supporting nervous fiber ingrowth [10]. Of these, electro-spinning technique and Self-Assembling Peptide amphiphiles (SAPs) have attracted attention for their reproducible synthesis and flexibility using techniques in tissue engineering [11].

The future, most likely will use a combination of techniques that encompass stem cells and self-assembled nanofibers that can form a scaffolding, however imprecise. For now, the drumbeat of hype is increasing to a crescendo but for hope to become reality, a 3D construct of the brain for chronic brain diseases that combines scaffolding techniques with stem cell research might yet reveal exciting results. The final piece of this puzzle would be to bring vascular supply to the voxel of tissue that is so constructed ant that could be the toughest challenge yet. Scientists working in 'silos' isolated in time and space and concentrating on their own angle without a cohesive network of ideas to construct a 3D brain tissue will most likely fail.

\section{References}

1. Noseworthy JH1, Lucchinetti C, Rodriguez M, Weinshenker BG (2000) Multiple sclerosis. N Engl J Med 343: 938-952.[Crossref]

2. Lee JY, Taghian K, Petratos S (2014) Axonal degeneration in multiple sclerosis: can we predict and prevent permanent disability? ActaNeuropatholCommun 2: 97.[Crossref]

3. van Munster CE, Jonkman LE, Weinstein HC, Uitdehaag BM, Geurts JJ (2015) Gray matter damage in multiple sclerosis: Impact on clinical symptoms. Neuroscience 303 : 446-461.[Crossref]

4. Schlaeger R, Papinutto N, Panara V, Bevan C, Lobach IV, et al. (2014) Spinal cord gray matter atrophy correlates with multiple sclerosis disability. Ann Neurol76: 568580.[Crossref]

5. Harris VK, Faroqui R, Vyshkina T, Sadiq SA (2012) Characterization of autologous mesenchymal stem cell-derived neural progenitors as a feasible source of stem cells for central nervous system applications in multiple sclerosis. Stem Cells Transl Med1: 536-547. [Crossref]

6. Harris VK, Yan QJ, Vyshkina T, Sahabi S, Liu X, et al. (2012) Clinical and pathological effects of intrathecal injection of mesenchymal stem cell-derived neural progenitors in an experimental model of multiple sclerosis. J NeurolSci313: 167-177.[Crossref]

7. Burt RK, Loh Y, Pearce W, Beohar N, Barr WG, et al. (2008) Clinical applications of blood-derived and marrow-derived stem cells for nonmalignant diseases. JAMA 299: 925-936.[Crossref]

8. Burt RK, Loh Y, Cohen B, Stefoski D, Balabanov R, et al. (2009) Autologous nonmyeloablativehaemopoietic stem cell transplantation in relapsing-remitting multiple sclerosis: a phase I/II study. Lancet Neurol 8: 244-253. [Crossref]

9. Laurent LC, Ulitsky I, Slavin I, Tran H, Schork A, et al. (2011) Dynamic changes in the copy number of pluripotency and cell proliferation genes in human ESCs and iPSCs during reprogramming and time in culture. Cell Stem Cell 8: 106-118.[Crossref]

10. Zhu W, O’Brien C, O’Brien JR, Zhang LG (2014) 3D nano/microfabrication techniques and nanobiomaterials for neural tissue regeneration. Nanomedicine (Lond) 9: 859-875. [Crossref]

11. Cui H, Webber MJ, Stupp SI (2010) Self-assembly of peptide amphiphiles: from molecules to nanostructures to biomaterials. Biopolymers 94: 1-18.[Crossref]

Copyright: (C2015 Avasarala JR. This is an open-access article distributed under the terms of the Creative Commons Attribution License, which permits unrestricted use, distribution, and reproduction in any medium, provided the original author and source are credited. 